\title{
The effect of surface treatment and salivary contamination on the tensile bond strength between acrylic custom tray and monophase polyvinyl siloxane impression material.
}

\author{
Dr Menon Prasad Rajagopal ${ }^{1}$, Dr Pramod Sankar ${ }^{2}$ \\ ${ }^{1,2}$ (Department of Prosthodontics/ Educare Institute of Dental Sciences KUHS, India )
}

\begin{abstract}
Monophase elastomeric impression materials are commonly used with acrylic custom trays. Every effort is made to maximize bonding between the two. Lot of studies have focused on variables like adhesive drying time, tray material and type of elastomer but very few have solely concentrated on efficacy of surface treatment and effect of salivary contamination of the custom tray. The objective of this study was to find out the most effective surface treatment for the custom tray and also find out the extent to which salivary contamination could affect bond strengths.

This invitro study was carried out in two parts using 40 samples. The materials used were Reprosil monophase impression materials and autoploymerizing acrylic blocks. The samples were divided into four groups of five samples each. The first part of the study concentrated on finding out the effect of surface treatment of the tray and the second part focused on the effect of salivary contamination. The specimens were tested in an Instron testing machine and the results of the study were interpreted by statistical analysis to arrive at the conclusions. The results showed statistically significant increase in tensile strengths for surfaces subjected to grit blasting and roughening with bur and decrease for specimens cured against wax. Salivary contamination of the tray prior to adhesive application decreased bond strengths significantly. It was concluded from the study that mechanical treatment of the tray prior to adhesive application maximizes adhesion of the impression material and that salivary contamination of the custom tray prior to adhesive application reduces adhesion between tray and elastomer regardless of the surface treatment carried out
\end{abstract}

Keywords: Acrylic custom tray, Monophase elastomer, salivary contamination, Surface treatment, Tensile bond strength.

\section{Introduction}

Elastomeric impression materials are currently the most popular final impression material in fixed prosthodontics. Their advantages surpass their disadvantages by a long way. Monophase or regular bodied elastomers are very versatile as they can be used as tray and syringe material[1]. The chink in the armor of these elastomers has been their bonding with the commonly used acrylic custom tray. Lack of bonding can cause inaccuracies in the cast and consequently the prosthesis. Surface treatment of the custom tray can enhance the bonding[2] and salivary contamination of custom tray could interfere with the bonding[3]. This study aims to investigate these factors which could influence bond strengths and suggest a favourable clinical protocol.

\section{Objectives}

The study aims to evaluate the tensile bond strength between the monphase elastomer/adhesive system and autopolymerizing acrylic custom tray after subjecting the tray to different surface treatments and find the most effective surface treatment. It also aims to determine the effect of salivary contamination on these bond strengths.

\section{Methodology}

This was an in vitro study which involved preparation of 40 autopolymerizing acrylic resin block samples and perforated copper plates. The resin blocks simulate the custom tray and the role of the copper plate was solely to retain the elastomer. The acrylic resin blocks (DPI Cold cure Dentsply India) were formed in copper molds of $1 \mathrm{sq}$ inch open at both ends. The samples were formed against wax (Charminar modeling wax no 2$)$ and aluminumfoil $(0.003 \mathrm{~mm}$ thickness). The perforated copper plates were of $1 \mathrm{sq}$ inch and had stops at the corners to maintain a distance of $3 \mathrm{~mm}$ with the acrylic blocks to simulate the thickness of the impression material Fig 1. The study was done in two parts, the first part using 20 samples to find the most retentive surface and the second part using the remaining 20 samples to assess the role of salivary contamination in decreasing bond strengths.

The 20 samples were divided into four groups (G1-G4) of ten each. Three groups were cured against aluminum foil and one against wax. Samples cured against wax were cleaned and dried. One group was the 
control group in which samples were formed against aluminum foil without any further treatment. The two other groups were subjected to mechanical surface treatments as follows, one group was subjected to alumina blasting (250 micron) for $1 \mathrm{~min}$, the others were roughened with a flame shaped acrylic trimming bur $(6 \times 10 \mathrm{~mm}$, ISO no 310, Hager and Meisenger, Germany). Tray adhesive (Caulk Tray adhesive- Dentsply International) was applied evenly to both the copper plate and acrylic block and dried for 15 mins. Regular body impression material (Reprosil- Dentsply International) was mixed according to manufacturers instructions and placed on the interface and samples were oriented. In the second part of the study the remaining 20 samples were divided in the same manner as described above. The samples were then contaminated with natural human saliva with a cotton tip applicator and dried. The remaining steps remained the same. The specimens were tested for tensile strength in an universal testing machine (Shimadzu Inc Japan) at the National Institute of Technology (NIT), Kozhikode Fig 2. Values were recorded and subjected to statistical analysis to come to the conclusions of the study.

\section{Results}

TABLE 1 and TABLE 2 shows the mean tensile strengths recorded in the four groups before and after salivary contamination respectively. Groups one to four were samples cured against aluminum foil without any surface modification (G1), wax (G2), samples subjected to grit blasting (G3) and those roughened with bur (G4) respectively. It was seen that samples used in the second part of the study i.e. after salivary contamination showed lower tensile strength values. It was also seen that samples cured against wax showed the lowest values and samples roughened with bur showed the highest values.

ANOVA analysis of variance TABLE 3 shows that there is significant difference between groups in both parts of the study. It also shows significant difference between groups of the two parts of the study. There was also no interaction which implies that the variable introduced does not affect the interaction between the groups studied. Scheffe test and Post Hoc tests which are depicted in TABLE 4 show that there is statistically significant difference between group cured against wax and all other groups, as also between aluminum foil group and bur roughened group. The other groups did not show any statistically significant difference among themselves. The ANOVA graph shows the interaction and suggests that the variable does not affect the interaction between the groups.

\section{Discussion}

Impression tray adhesives for polyvinyl siloxane impression material are chemically a combination of polydimethyl siloxane and ethyl silicate[4]. Polydimethyl siloxane bonds chemically with the silicone impression material whereas ethyl silicate forms a hydrated silica gel which bonds physically with the tray material. As the bond between the tray and adhesive is purely mechanical it is important to achieve maximum adhesion at this interface to achieve optimal clinical results[5].

Results of the first part of the study indicate that the most retentive surface is obtained by roughening with a bur and the least retentive surface is that formed against wax. This finding corroborates with earlier studies where authors have advocated burnishing a tin foil against a wax spacer prior to fabricating the tray[ $6^{]}$. ANOVA table and graph Fig3\&4 respectively suggests that alumina blasting is not very effective in plastic surfaces. Alumina blasting produces a etched surface and the adhesive being viscous may not wet the surface. The large irregular spaces created by bur may be more conducive to wetting by the adhesive[7]. Analysis of bond failure in specimens show that in G4 most of the spacer remained on the acrylic whereas in G2 no adhesive remained on the acrylic. The first part of the study leads us to imply that surface treatment in form of grit blasting and roughening with bur definitely increases bond strengths and that forming a tray against wax decreases bond strengths significantly.

Salivary contamination of the samples significantly decreased bond strengths which corroborate the findings of Wang, Nguyen et al (1995)[8 ]and Chai, Jameson et al (1991). They had tested the effect of artificial saliva on shear bond strengths. The clinical implications of this study are that proper cleaning, drying of the tray are necessary before application of adhesive and also some form of surface treatment of the tray especially trimming with a bur helps maximize bond strengths. The formulation of a clinically acceptable value as bond strength is difficult due to the fact that different impression adhesive systems have differing standards and moreover rigidity of impression material and presence of undercuts would affect the values required. Some authors have recommended thermoplastic trays as they have shown higher bond strengths[9]. Since standards are presently lacking, it is recommended that every attempt is made to maximize adhesion of the impression adhesive. 


\section{Figures And Tables}

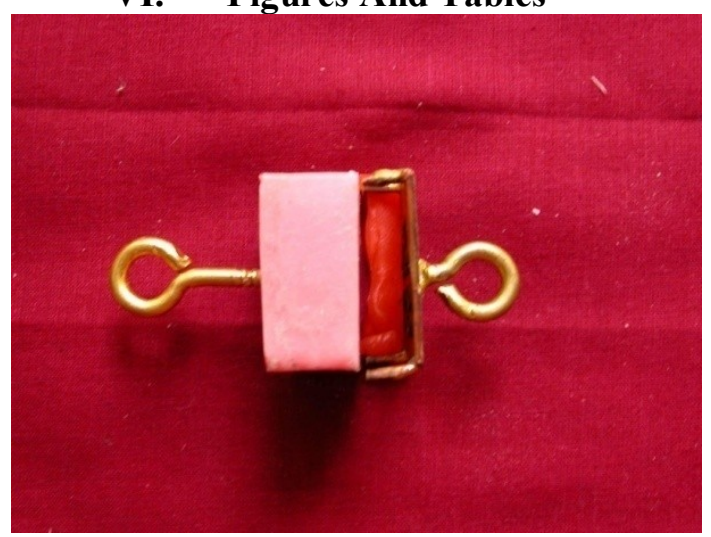

Figure1- Prepared samples

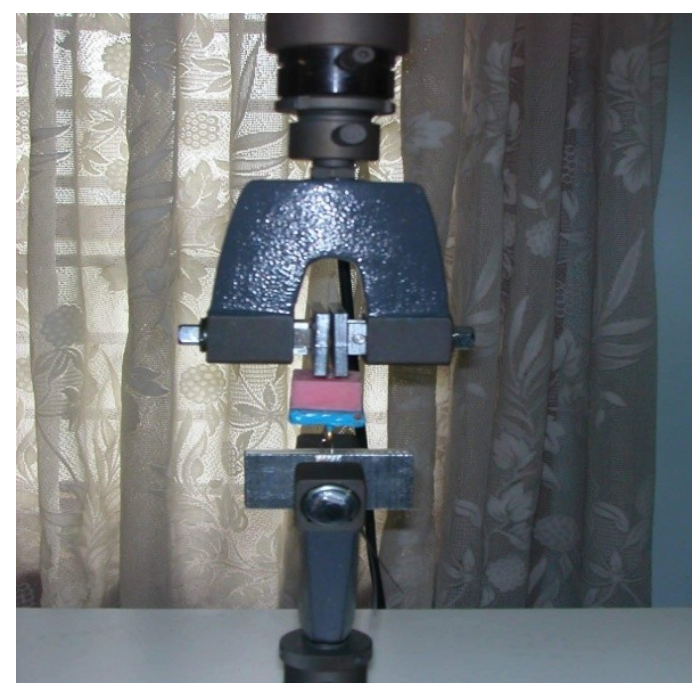

Figure2- Instron testing machine

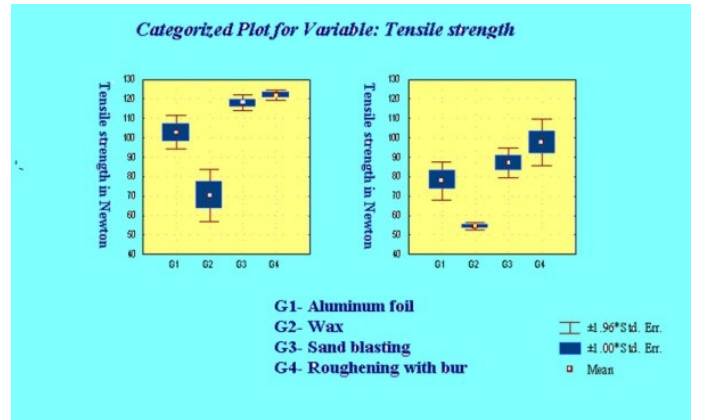

Figure3- Comparison of different surface treatments

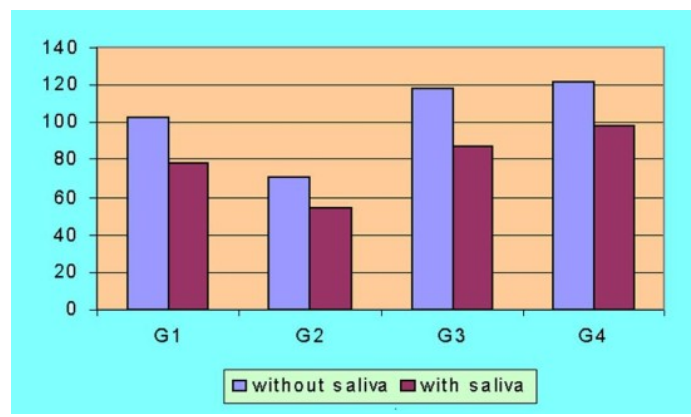

Figure4- Analysis of variance graph 


\begin{tabular}{|c|c|c|c|c|}
\hline$N O$ & Aluminum foil & Wax & Sand blasting & Roughening with bur \\
\hline 1 & 112.375 & 80.5312 & 112.375 & 125.343 \\
\hline 2 & 92.3906 & 72.3215 & 115.234 & 124.906 \\
\hline 3 & 91.7187 & 73.6406 & 123.865 & 119.265 \\
\hline 4 & 108.984 & 81.0468 & 116.342 & 120.365 \\
\hline 5 & 108.359 & 43.7500 & 121.893 & 119.453 \\
\hline
\end{tabular}

Table2- Tensile strength after salivary contamination in Newtons

\begin{tabular}{|l|l|l|l|l|}
\hline No & Aluminum foil & Wax & Sand blasting & $\begin{array}{l}\text { Roughening } \\
\text { bur }\end{array}$ \\
\hline 1 & 73.9062 & 51.8125 & 89.5812 & 115.762 \\
\hline 2 & 66.4562 & 55.6875 & 96.3250 & 108.043 \\
\hline 3 & 69.9812 & 52.7562 & 92.1250 & 84.0500 \\
\hline 5 & 87.3154 & 55.1187 & 82.5312 & 91.7250 \\
\hline
\end{tabular}

Table3- Analysis of variance table for comparison of group and time

\begin{tabular}{|l|l|l|l|l|l|l|l|}
\hline & Df effect & MS effect & DF error & MS error & F value & P-level & \\
\hline Group & 3 & 4351.97 & 32 & 94.0385 & 46.2786 & 9.63 E-12 & S \\
\hline Time & 1 & 5729.08 & 32 & 94.0385 & 60.9227 & 6.66 E-09 & S \\
\hline Interaction & 3 & 96.6563 & 32 & 94.0358 & 1.02783 & 0.3933 & NS
\end{tabular}

Table4- Scheffe test and Probabilities for Post Hoc tests

\begin{tabular}{|l|l|l|l|l|}
\hline & G1 & G2 & G3 & G4 \\
\hline Mean & 90.36513 & 62.34622 & 102.4628 & 109.7878 \\
\hline G1 & & $5.63 E-06$ & 0.069558 & 0.001242 \\
\hline G3 & $5.63 E-06$ & & $3.61 E-09$ & $6.37 E-11$ \\
\hline G4 & 0.069558 & $3.61 E-09$ & & 0.427694 \\
\hline
\end{tabular}

If $\mathrm{P}<0.01$, the difference is highly significant.

If $\mathrm{P}<0.05(\mathrm{P}>0.01)$, the difference is significant at $5 \%$.

If $\mathrm{P}>0.05$, the difference is not significant.

\section{Conclusions}

It was concluded from within the limitations of the study that forming the tray against wax decreases bond strengths and hence is not advisable. Physical treatment of the custom tray either by alumina blasting or roughening with bur prior to adhesive application can significantly increase bond strengths and that salivary contamination of the tray prior to adhesive application significantly decreased bond strengths irrespective of subsequent surface treatments.

\section{References}

[1] Tylman S.D, Malone W.F.P, Tylmans theory and Practice of fixed Prosthodontics $8^{\text {th }}$ Ed ( St Louis, CV Mosby Co 1997) .

[2] Davis G.B, Moser J.B, Brinsden G.I: The bonding properties of elastomer tray adhesives. J Prosthet Dent, 36, 1976, 278-285.

[3] Chai J.Y, Jameson L.M, Moser J.B: Adhesive properties of several impression material systems: Part- I. J Prosthet Dent, 66, 1991, 201-209.

[4] Phillips R.W, Science of dental materials $9^{\text {th }}$ ed,( Philadelphia. WB Saunders Co, 1991)

[5] Samman J.M, Fletcher A.M: A study of impression tray adhesives. Quintessence Intl,4, 1985, 305-309.

[6] Johnston J.F, Phillips R.W, Dykema R.W, Modern Practice in Crown and Bridge Prosthodontics, $3^{\text {rd }}$ ed (Philadelphia 1971, WB Saunders Co)

[7] Mohd Sulong Z.A, Setchell D.J: Properties of the tray adhesive of and addition polymerizing silicone to impression tray materials. J Prosthet Dent 1991, 66, 743-747.

[8] Wang R.R, Nguyen T, Boyle A.M: The effect of tray material and surface condition on the shear bond strength of impression materials L Prosthet Dent 1995, 74, 449-454.

[9] Dixon D.L, Breeding L.C, Brown J.S: The effect of custom tray material type and adhesive drying time on the tensile bond strength of an impression material/adhesive system. Int J Prosthodont, ,7, 1994, 129-133. 